ORIGINAL ARTICLE

\title{
Influence of weekly physical exercises on indicators of biological age of student's youth
}

\author{
Stanislav Prysiazhniuk ${ }^{1 \mathrm{ABCDE}}$, Oleksander Pryimakov ${ }^{2 \mathrm{ABCDE}}$, Sergii Iermakov ${ }^{3 \mathrm{ACDE}}$, Dmytro Oleniev $^{4 \mathrm{ABCDE}}$, \\ Jerzy Eider ${ }^{5 \mathrm{ADE}}$, Natalija Mazurok ${ }^{6 \mathrm{CDE}}$ \\ ${ }^{1}$ State University of Telecommunications, Ukraine \\ ${ }^{2,5}$ Institute of Physical Culture Sciences, Szczecin University, Poland \\ ${ }^{3}$ Gdansk University of Physical Education and Sport, Poland \\ ${ }^{4}$ The National Defense University of Ukraine named after Ivan Cherniakhovskyi, Ukraine \\ ${ }^{6}$ National Pedagogical Dragomanov University, Ukraine
}

Authors' Contribution: A - Study design; B - Data collection; C - Statistical analysis; D - Manuscript Preparation; E - Funds Collection

\section{Abstract \\ Background and Study Aim}

\section{Material and Methods}

Results

Conclusions

Keywords:
The physical activity level of students is closely associated with ecological, hygienic, and socioeconomic facts. This is especially true during the COVID-19 pandemic, which has dramatically reduced the student opportunity to engage in regular physical activity. The purpose of the work is to study the influence of the weekly physical exercises on the indicators of biological age of students of higher education institutions of Ukraine.

The study involved 409 students (182 boys and 227 girls), who were divided into experimental (87 boys and 117 girls) and control (95 boys and 110 girls) groups. The biological age (BA) of students was determined by means of Voitenko's method using biomarkers of their physical status. Indices of the cardiovascular system (pulse, systolic, and diastolic blood pressure); respiratory system (vital capacity, the Hench and Stange test); central nervous system (static balancing); PHSA (personal health self-assessment) were studied. In addition, a questionnaire-based survey of students on their health self-assessment including 27 questions was carried out. Statistica 13.5 statistical software package was used to process the experimental material. Methods of variation statistics, correlation, and regression analysis were used. The coefficients of the Student $t$-test and Fisher's F-test were calculated.

In the process of pedagogical experiment, the positive impact of the author's physical education program on BA of students of the experimental group (EG) was revealed: in boys, the positive dynamics of BA changes was detected already after four additional hours of performing exercises per week, whereas in girls - after six or more hours. The most pronounced changes in physical state, which determined BA decrease during academic year were noted in students with a weekly motor regime exceeding 6 hours. In boys of EG, the biological age decreased at the end of the experiment by 11,1 years $(p<0,001)$, whereas in girls - by 5,3 years $(p<0,001)$. No positive changes of BA were observed at the end of the experiment in students of the control group (CG), whose weekly regime of motor activity constituted 2 hours. In boys of EG, the decrease of BA is manifested after four additional hours of performing physical exercises per week, whereas in girls - after six or more hours. The most pronounced changes in BA indices during the academic year were noted in students of the experimental group with weekly motor regime exceeding 6 hours.

The developed mathematical models are recommended to be used for estimating, modelling, and predicting the biological age of students according to informative indices of physical state. biomarkers, higher education, physical activity, health, COVID-19

\section{Introduction}

The system of physical education in higher education institutions should be a reliable basis for a high level of physical and mental working capacity, intellectual development of students in the learning process. It should encourage students to exercise regularly, to form the physical development necessity and ensure a high level of health and professional longevity. During the COVID-19 pandemic, there was an urgent need to orient the physical education system to solving the problems of the sedentary lifestyle of students.

The priority task of the system of physical education

(c) Stanislav Prysiazhniuk, Oleksander Pryimakov, Sergii lermakov, Dmytro Oleniev, Jerzy Eider, Natalija Mazurok, 2021

doi:10.15561/20755279.2021.0108 in higher education institutions is the formation of a healthy, physically and spiritually growth personality, the development of effective means to compensate for the adverse effects of hypodynamic and hypokinesia on the body of school and student youth [1-4]. Solving such problems in conditions of limited movement of people and confined spaces requires the search for effective approaches. To this should be added the transition of universities to distance learning forms, which are not typical for the physical education system. The emergence of these problems coincided with the need for changes in the higher education system.

The reformation of higher education in Ukraine is accompanied by the emergence of innovative higher 
education institutions, the characteristic feature of which is the increase in the volume and intensification of education $[2,5]$.

Education intensification is also peculiar for universities of other countries. The studies show that:

- The combination of new challenges in higher education with the development of mobile technologies (one of the pillars of digital transformation) leads to intensification in study opportunities and requirements for the development of new teaching methods [6]

- Particular attention should be paid to business cooperation in creating a single educational space within the frames of relation intensification in the educational process [7].

Other authors [8] investigated the issue of the information load on Russian students increase in connection with the academic load in a situation of information overload. The authors noted that modern conditions require more and more adaptation to stressful situations that students are exposed to in the situation of educational activity.

It is known that an increase in study load volume results in decreased motor activity of students. This is supported by numerous studies. Griban et al [9] found that the level of physical fitness of Ukrainian boys and girls of the 1-4 courses is unsatisfactory in general. Guthold et al [10] described the current prevalence and trends of insufficient physical activity of school children aged 11-17 according to countries, regions, and worldwide. The authors noted that the majority of adolescents fail to meet existing standards of physical activity. Thomas et al [11] examined the frequency, intensity, time, type of physical activity, and the obstacles to engaging in it among Canadian students during their first year of study at university. The authors noted that programs to promote different aspects of physical activity should be focused on: non-competitive sports and fun activities; activities that students can engage in during their leisure time.

Decreased motor activity volume of young people and students was noted by researchers from Vietnam [12], Poland [13], Britain [14), and other countries. According to the authors, the physical inactivity of young people is one of the major determinants of their physical development lag from the current norms $[9,14]$ and physical health deterioration $[1,12,13]$. Dao Chanh Thuc [12] pointed out that the growth of the aging rate of Vietnamese student youth is due to decreased motor activity and reproductive function. The impact of motor activity regime on the biological age of females aged 17 - 18 was revealed. Cumming et al. [14] investigated the biological maturity, body size, and motor activity of British youth. While noting the association between them, the authors failed to fully disclose the specifics of physical exercise impact on BA.

As a rule, extensive introduction of the latest pedagogical technologies in accordance with the requirements of the Bologna Declaration is carried out without prior physiological and hygienic research. The processes of adaptation of student youth, within the implementation of innovative pedagogical technologies of learning, are insufficiently studied. A significant increase in mental workload leads to increased hypodynamic and hypokinesia, catastrophic limitation of muscular effort, and, together with excessive fascination of young people with computer games, contributes to various diseases, deterioration of physical condition and reduced physical and mental performance [15-17].

In the context of the COVID-19 pandemic, the scientific and pedagogical staff of the departments of physical education and sports clubs of universities cannot provide the necessary level of physical fitness and health of students. To the low level of students' functional capabilities, there is also a limitation of their physical activity.

Therefore, attempts to achieve a higher level of physical activity of students lead to the fact that the educational process of physical education comes into conflict with theoretical disciplines.

The shortcomings of physical education at secondary schools cannot be compensated without harming the health of students and without making changes to the general educational process in higher education. Only by laying the foundation of physical development and physical fitness of infants and ensuring the continuity of physical education at each stage of ontogenesis the necessary health of young people can be achieved $[1,15$, $18,19]$. As a result, there is a critical situation regarding the physical and mental health of student youth.

Our and other studies of functional indicators of body systems of the first-year students indicate that a significant proportion of students have low health and unsatisfactory levels of physical fitness, $[3,19,20]$. The studies have shown that the deficit of physical activity for maintaining satisfactory health and physical fitness of students ranges from $50 \%$ to $70 \%$ of the required. A number of authors believe that a significant role is played by socio-economic factors, environmental problems, lack of priority motivation of students for a healthy lifestyle as a major factor in the formation, strengthening, preservation and restoration of health and transmission to future generations $[21,22]$.

The physical activity level of students is closely associated with ecological, hygienic, and socioeconomic facts. This is especially true during the COVID-19 pandemic, which has dramatically reduced the student opportunity to engage in regular physical activity.

Huckins et al [23] examined student behavior and mental health in response to the COVID-19 pandemic compared to previous periods of time. They found that compared to previous semesters students during the winter 2020 semester were more sedentary, anxious and depressed. The wide variety of behavior models included more frequent phone use, decreased physical activity, and less number of visited places.

Zhang et al [24] assessed the negative impact of the COVID-19 outbreak upon the mental health of Chinese students and examined possible strategies for mitigating 
the consequences. They noted that that possible strategy for mitigating consequences and thus, improving mental health should include an adequate level of daily physical activity and good sleep.

Gallo et al [25] studied the level of physical activity (Active Australia Survey) among third-year biomedical students. The results were compared to those of students of the same course, who studied two years before. The authors found that the pandemic affected the physical activity level of both sexes, with $30 \%$ fewer students achieving "sufficient" activity levels (minimum 150 minutes over five sessions) compared to the previous two years.

Romero-Blanco et al [26] assessed the physical activity and sedentary lifestyle of students before and during isolation from the coronavirus. The findings demonstrated the reduction of physical activity and sitting time globally and across groups.

It is safe to conclude that the situation with the COVID-19 contributes to further decrease of student motor activity level.

The survey, conducted by us, has showed that $30,4 \%$ of $1^{\text {st }}$ and $2^{\text {nd }}$ year students rate their health as good, $58,6 \%$ - satisfactory, $10,6 \%$ - poor and only $0,4 \%$ of the total number of respondents consider their health very bad [27]. At the same time, there is a significant difference between the self-assessment of students' health and the results of annual medical examinations. Similar data were obtained in the study of the physical health selfassessment by university students of Gomel (Belarus) [28]. It was revealed that $58.5 \%$ of the respondents assess their physical health as satisfactory, and $67.6 \%$ consider their physical activity as moderate. Hossain et al [29] examined the association between physical health selfassessment and depression and anxiety in university students of Dhaka, Bangladesh. It turned out that 13,9\% of respondents had poor self-assessment of health, and $49,9 \%$ - had dissatisfaction with self-assessment of body image.

One of the factors that characterize the state of human health is indicators of biological age (BA) [20, 30-32]. Several foreign authors studied the relationship between the level of BA, health status, and aging, age-related morbidity and risk of death [33-37]. For instance, Jinho et al [33], Jee et al [38] developed biomarkers and models for predicting BA, aging, survival, and risk of death of Koreans. The clinical usefulness of developed models for the practical diagnosis of aging was verified. Zhong et al. [35] determined a set of physiological markers of the rate of aging, life expectancy, and health of Chinese people in the age range 50 plus years. It was proposed to differentiate biologically old from young people of the same chronological age according to them. Brazilian researchers [39] demonstrated that with an increase in the biological and chronological age of children and adolescents aged 9-15, their physical activity decreases. Boys were revealed to be more physically active than girls, however, when biological maturation is controlled, sex differences disappear. Belsky et. al. [37] developed the methods for evaluating the biological aging of young people without age-related diseases. They showed that rapidly aging Americans were less physically fit, experienced the decline of cognitive functions and aging of the brain, reported worse health status, and looked older. The measurement of biological aging in young people is proposed to be used to identify the causes of aging and to evaluate methods of rejuvenation. German scientists [40] used markers of oxidative stress, protein glycation, inflammation, cellular senescence, and hormonal regulation to determine biological age and compare it with chronological age, as well as to identify persons at high risk of developing age-related degenerative diseases or disability.

It is known that regular physical exercises may influence biological age. Pavanello et al [41] assumed that intensive relaxing practices may impact various molecular mechanisms of aging. Canadian researchers [36] examined the relationship of BA physiological markers with chronological age, physical development, cognitive functions, physical work capacity, and morbidity in persons aged 45-85. Sez differences were insignificant in this case. Rahman et al [42] developed an approach to biological age prediction using a person's physical activity recorded by a wearable device. They claim that the suggested method leads to efficiency improvement. Ajman et al [43] argue that data on biological development levels are of great significance for young athletes. Goto et al [44] studied the impact of biological maturity on the results of elite and junior football matches. The authors note that the coaches should be aware of the process of identifying and developing talent as far as the maturity may influence the results of running at high speed. Lesinski et al [45] studied the control values of anthropometric and physical fitness percentiles for adults, age, and sex of young elite athletes. They recommend using percentiles in practice as approximate criteria to identify and develop talents.

The results of the analysis of national and foreign sources showed that BA studies were aimed primarily at identifying informative markers of BA correlating with rates of aging, diseases, life expectancy, and the risk of death. Most of the studies were conducted on middleaged and elderly people. In the works dealing with the study of young people BA, the causes and mechanisms of biological aging have not been sufficiently disclosed. The information about motor activity influence on BA and the rate of aging, morbidity, and life expectancy can hardly be considered sufficient.

Incomplete coverage of the issue under consideration, different approaches, and methods of its study, the inconsistency of findings, necessitate a deeper examination of BA, in particular, its relationships with health status, aging rates, gender, age, motor activity, socio-economic and ecological living conditions.

This prompted us to conduct scientific and pedagogical research to determine the interrelation between biological age and the amount of weekly physical activity of students. We assume that the results of this study may be especially important in a new and unexpectedly emerging 
sanitary and epidemiological situation - the COVID-19 pandemic. This assumption is based on the fact that the mathematical models developed by us can be used to assess, model and predict the biological age of students by informative indicators of their physical condition.

The purpose of the work is to study the influence of the weekly physical exercises on the indicators of biological age of students of higher education institutions of Ukraine.

\section{Materials and Methods}

\section{Participants.}

We involved students of higher education institutions of Ukraine to conduct a study. The total number of students, who participated in the study, was 409 people ( $n=182$ - boys; $n=227$ - girls), which were divided into experimental group (EG) ( $\mathrm{n}=87$ - boys; $n=117$ - girls) and control group (CG) ( $n=95$ - boys; $n=110$ - girls). The experimental group students were divided into 3 subgroups: $\mathrm{EG}_{1}, \mathrm{EG}_{2}$ and $\mathrm{EG}_{3}$.

Study protocol was approved by Ethic Committee State University of Telecommunications (Kyiv, Ukraine). The research was fulfilled in compliance with WMA Declaration of Helsinki - Ethical Principles for Medical Research Involving Human Subjects [46].

\section{Research Design.}

The control groups practiced once a week according to the generally accepted physical education program approved by the Ministry of Education and Science of Ukraine [47]

The experimental groups were engaged in physical exercises according to the experimental program. Experimental program provided: two hours of physical education classes per week; two to six additional independent physical exercises. Experimental methodology for students of $\mathrm{EG}_{1}$ envisaged two hours of academic studies during the week and two hours of independent exercises. For students of $\mathrm{EG}_{2}$, the program included two hours of academic studies during the week and four hours of independent exercises. Students of $\mathrm{EG}_{3}$ were offered a program of two hours of academic studies during the week and six or more hours of independent exercises.

The research was conducted during the school year (the study was conducted before the onset of the COVID-19 pandemic).

To determine the biological age, we chose the Voitenko's [48] method. In accordance with Voitenko's method, indices of physical state were registered to determine the biological age. In addition, a questionnairebased survey of students on their health self-assessment including 27 questions was carried out. Indices of the cardiovascular system (pulse, systolic and diastolic blood pressure), respiratory system (vital capacity, the Hench and Stange test), central nervous system (static balancing); PHSA (personal health self-assessment) were studied.

Statistical analysis. STATISTICA 13.5 statistical software package was used to process the experimental material. Methods of variation statistics, correlation, and regression analysis were used [49]. The coefficients of Student t-test and Fisher's F-test were calculated to determine the validity of obtained results.

\section{Results}

The analysis of research materials of boys and girls from the control and experimental groups is represented below. Analysis of the obtained results in the control group showed no positive effect from physical education classes in the amount of 2 hours per week during the school year. In some cases, there was a negative impact of physical education classes on the well-being of student youth over the next few days (muscle pain, poor sleep, loss of appetite, sometimes headaches, etc.). Indicators of biological age of young men in the control group were higher than the corresponding indicators on average over the university, although statistically unlikely $(49,3 \pm 0,77$ years vs. 49,0 $\pm 0,88$ years; $p>0,05$ ) (Fig. 1 ).

There was similar situation in the control group of the girls $(39,6 \pm 0,79$ vs. $39,5 \pm 0,66 ; p>0,05)$ (Fig. 2).

Experimental group 1. Representatives of both sexes of $\mathrm{EG}_{1}$ had similarities in the results, but there was also some difference. Thus, the negative effects of compulsory physical education and 2 hours of self-study were more pronounced among boys than girls.

Indicators of biological age of boys in this subgroup significantly exceeded the university average (52,5 \pm $0,46$ vs. $49,0 \pm 0,88 ; \mathrm{p}<0,001)$, which indicated a high level of statistical probability (Fig. 1). The indicators of biological age of girls from the experimental group 1, although increased, but not as among boys $(40,4 \pm 1,09$ vs. $39,5 \pm 0,66 ; p>0,05)$ (Fig. 2). It should be noted that such amount of weekly motor regime did not sufficiently meet the requirements of the body; independent exercise was conducted at a low methodological level and was not effective. There is a necessity for qualified methodological assistance from the scientific and pedagogical staff of the Department of Physical Education. Therefore, one of the shortcomings of this system is the lack of full pedagogical control by scientific and pedagogical staff of the Department of Physical Education.

Experimental group 2. A positive effect from a certain system of health and training classes was observed among the boys from the $\mathrm{EG}_{2}$, as evidenced by changes in biological age, namely $-46,4 \pm 0,45$ vs. $49,0 \pm 0,88$ (p $<0,001)$.

The results of this subgroup confirm the position that in order to obtain the desired effect from exercise in a higher education institution, it is necessary to focus on the 6-hour motor regime of young students. This is the minimum number of hours of exercise that will allow young freshmen to effectively influence the functional activities of the body [under the condition of pedagogical control by research and teaching staff of the Department of Physical Education] and, consequently, more successfully master the curriculum.

The situation among the girls of this subgroup is similar to that in the first subgroup. The results almost coincide (Fig. 2). Minor changes in biological age (40,5 \pm $0,91$ vs. $39,5 \pm 0,66 ; p>0,05)$, suggest that for girls it is 


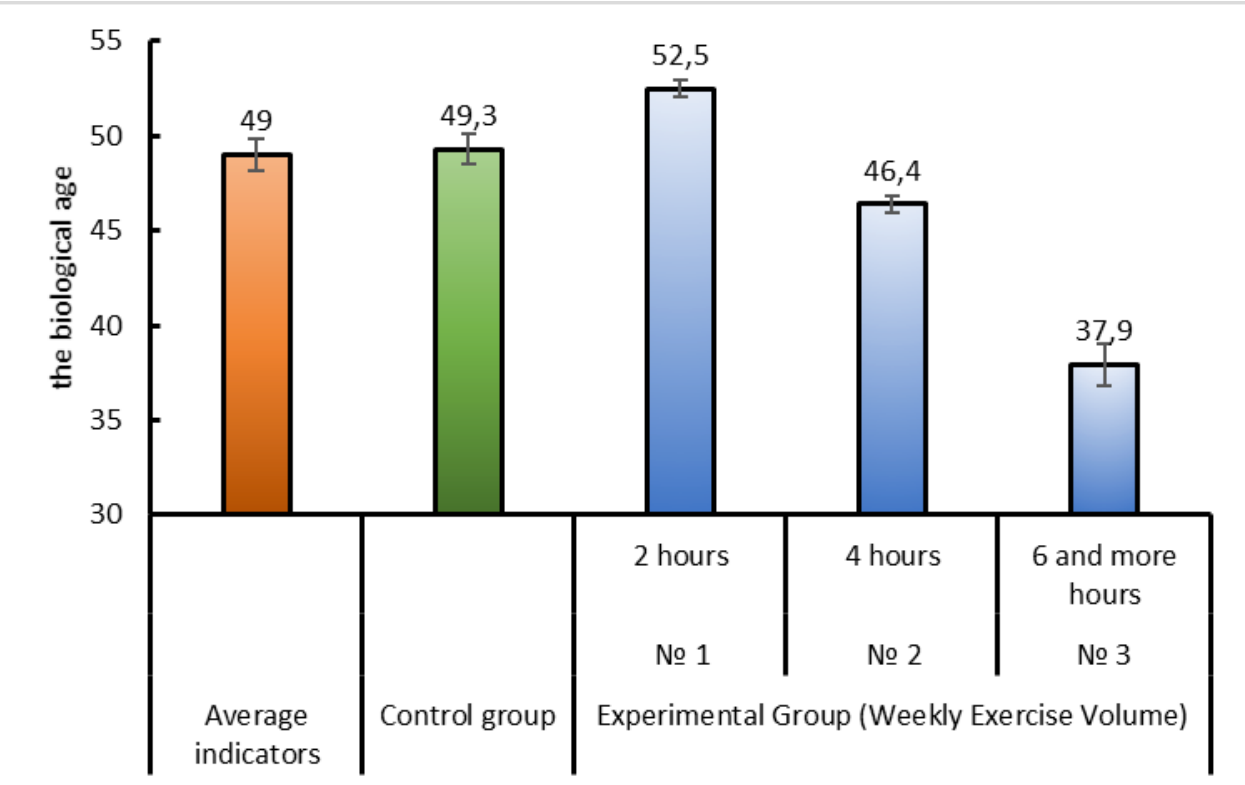

Fig.1. The dependence of the indicators of biological age of $1^{\text {st }}$ year boys on the weekly amount of physical activity during the school year $[n=182]$

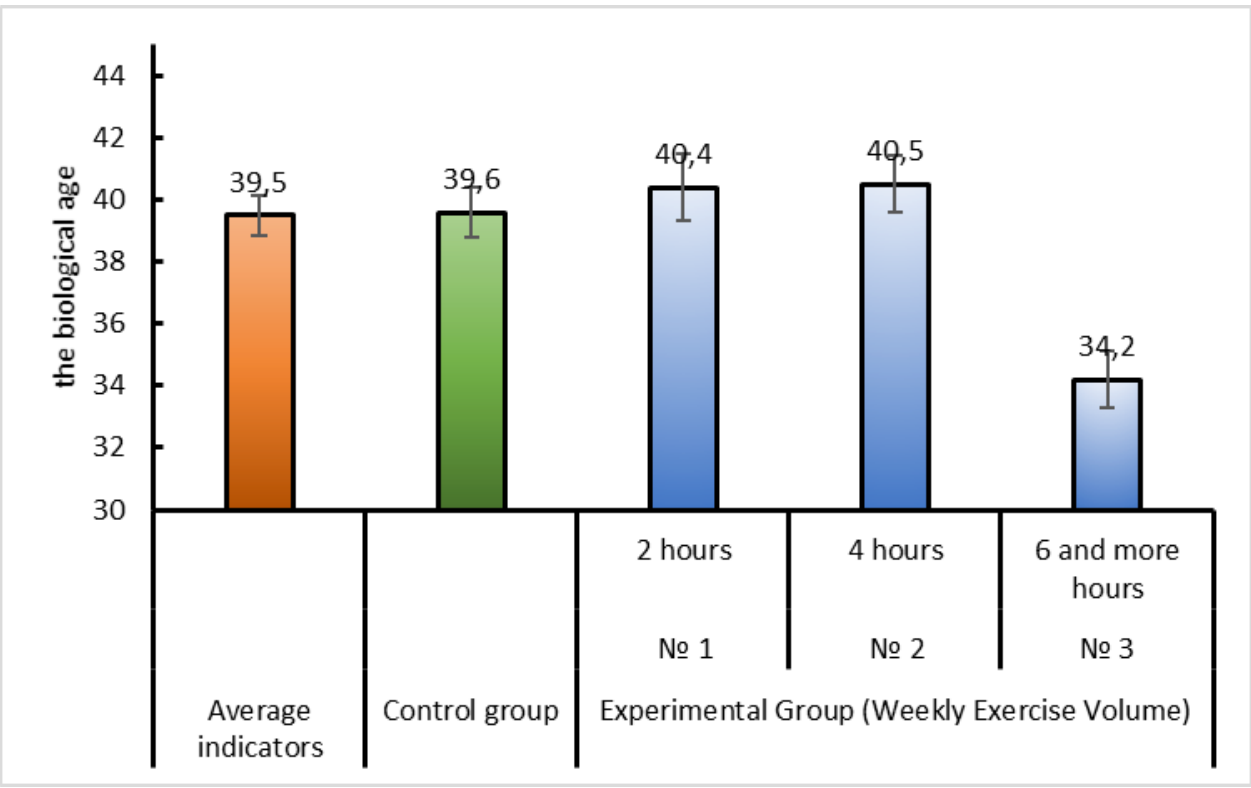

Fig. 2. The dependence of indicators of biological age of the girls of $1^{\text {st }}$ year on weekly volume of physical activities during the school year $[n=227]$

necessary to review this system of exercise. It proved to be ineffective. In addition, it is necessary to take into account the psychological and emotional state of the girls. Usually they want to get a positive result quickly, with the least effort, ignoring the methodological recommendations of scientific and pedagogical staff of the Department of Physical Education. It is not uncommon for the girls to put in the first place the opinion of a friend, acquaintance, and not qualified methodological advice during physical exercises. In addition, the research and teaching staff of the Department of Physical Education (especially men) must take into account the vulnerability and psychology of the girl and feel the limit beyond which, if you cross, you can lose confidence and authority among students.
Experimental group 3. The best result was obtained in this subgroup $-\mathrm{EG}_{3}$ (Fig. 1, 2). Thus, the indicators of biological age in both boys and girls at the end of the experiment are much lower than average $-37,9 \pm 1,10$ vs. $49,0 \pm 0,88 ; \mathrm{p}<0,001$; in girls $-34,2 \pm 0,90$ against 39,5 $\pm 0,66 ; \mathrm{p}<0,001$.

Below are presented the mathematical models, correlation ( $\mathrm{r}$ ), and determination (d) coefficients reflecting biological age (BA) dependence on anthropometric and functional indices in male and female students in the process of the experiment (tabl. 1).-

In girls of the CG, the degree of BA dependence on the model parameters is somewhat higher than in those of the EG, both before and after the experiment (tabl. 1). 
Table 1. Mathematical dependence models of the biological age of males and females of EG and CG on anthropometric and functional indices before and after the experiment

\begin{tabular}{|c|c|c|c|c|c|}
\hline Grol & ups, condition & & Regression models & $\mathbf{r}$ & d \\
\hline \multirow{4}{*}{ 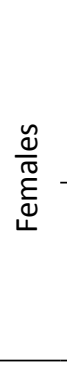 } & \multirow{2}{*}{$\begin{array}{l}\text { Before } \\
\text { experiment }\end{array}$} & EG & $\begin{array}{l}y=28,29+\left(0,792 x_{2}+0,304 x_{1}-0,215 x_{8}-0,120 x_{6}-0,005 x_{7}\right) \pm 2,4 \\
F=17,5 p<, 00000 . .\end{array}$ & $\begin{array}{l}0.886 \\
p<0.0000\end{array}$ & $\begin{array}{l}0.740 \\
p<0.0000\end{array}$ \\
\hline & & CG & $\begin{array}{l}y=8,23+\left(0,387 x_{1}+0,806 x_{2}-0,158 x_{8}-0,11 x_{6}-0,003 x_{7}\right) \pm 1,1 \\
F=204,9 p<, 00000 .\end{array}$ & $\begin{array}{l}0.988 \\
p<0.0000\end{array}$ & $\begin{array}{l}0.972 \\
p<0.0000\end{array}$ \\
\hline & \multirow{2}{*}{$\begin{array}{l}\text { After } \\
\text { experiment }\end{array}$} & EG & $Y=\left(15,18+0,174 x_{1}\right) \pm 2,6, F=23,9 p<, 00000$ & $\begin{array}{l}0.679 \\
p<0.0000\end{array}$ & $\begin{array}{l}0.442 \\
p<0.00004\end{array}$ \\
\hline & & CG & $\begin{array}{l}y=14,4+\left(0,351 x_{1}+0,806 x_{2}-0,155 x_{8}-0,12 x_{6}-0,04 x_{7}\right) \pm 0,7 \\
F=397,8 p<, 00000 . .\end{array}$ & $\begin{array}{l}0.994 \\
p<0.0000\end{array}$ & $\begin{array}{l}0.986 \\
p<0.0000\end{array}$ \\
\hline \multirow{4}{*}{$\frac{\check{\omega}}{\sum^{\pi}}$} & \multirow{2}{*}{$\begin{array}{l}\text { Before } \\
\text { experiment }\end{array}$} & EG & $\begin{array}{l}y=45,71+\left(0,167 x_{1}+0,653 x_{2}+0,077 x_{9}-0,13 x_{6}-0,004 x_{7}-0,11 x_{10}\right) \pm 0,57 \\
F=563,8 p<, 00000 . .\end{array}$ & $\begin{array}{l}0.996 \\
p<0.0000\end{array}$ & $\begin{array}{l}0.988 \\
p<0.0000\end{array}$ \\
\hline & & CG & $\begin{array}{l}y=41,82+\left(0,183 x_{1}+0,817 x_{2}+0,12 x_{9}-0,15 x_{6}-0,004 x_{7}-0,11 x_{10}\right) \pm 1,5 \\
F=81,0 p<, 00000 . .\end{array}$ & $\begin{array}{l}0.968 \\
p<0.0000\end{array}$ & $\begin{array}{l}0.925 \\
p<0.0000\end{array}$ \\
\hline & \multirow{2}{*}{$\begin{array}{l}\text { After } \\
\text { experiment }\end{array}$} & EG & $y=\left(52,5-0,107 x_{10}\right) \pm 2,6 F=3,9 p<, 00001$ & $\begin{array}{l}0.598 \\
p<0.0000\end{array}$ & $\begin{array}{l}0.343 \\
p<0.00001\end{array}$ \\
\hline & & CG & $\begin{array}{l}y=42,1+\left(0,18 x_{1}+0,749 x_{2}-0,13 x_{6}-0,0006 x_{7}\right) \pm 2,9 \\
F=81,0 p<, 00000 .\end{array}$ & $\begin{array}{l}0.882 \\
p<0.0000\end{array}$ & $\begin{array}{l}0.779 \\
p<0.0000\end{array}$ \\
\hline
\end{tabular}

NOTE: $y$-BA, years; $x_{1}$-arterial systolic pressure, $\mathrm{mm} \mathrm{Hg}$; $\mathrm{x}_{2}$ - health self-assessment; $\mathrm{x}_{3}$ - body mass, kg; $\mathrm{x}_{4}-\mathrm{height}$, $\mathrm{cm} ; \mathrm{x}_{5}$ - left hand strength, $\mathrm{kg} ; \mathrm{x}_{6}$ - static balancing, $\mathrm{s} ; \mathrm{x}_{7}$ - vital capacity, $\mathrm{ml}$; $\mathrm{x}_{8}$ - arterial diastolic pressure, $\mathrm{mm} \mathrm{Hg;}$ $x_{9}-$ Gench test, $s ; x_{10}-$ Stange test, $s ; r$-correlation coefficient; $d$-determination coefficient.

At the same time, as illustrated above, a more pronounced (statistically significant) decrease in the BA level was observed in the girls of the third EG group by the end of the experiment. This reflects the effectiveness of the developed physical education program for this group and the adequacy of the presented regression models.

Before the experiment, in males of the $\mathrm{CG}$ and the EG close correlation and determination coefficients were observed, reflecting a high level of predicting their BA according to the parameters of the developed models. After the experiment, the prognosis of BA in males of the $\mathrm{CG}$ according to the developed models decreased by $14 \%$ and constituted $77.9 \%(d=0.779, p<0.0000)$, whereas in those of the EG, the prognosis of BA according to the studied parameters decreased from $92.5 \%$ to $34.3 \%(p<0.00001)$. A decrease in BA dependence in males of the third EG on the studied morphofunctional parameters occurs when their BA decreases by the end of the experiment. A high reliability degree of the developed equations suggests that they can be used to model and predict BA of students depending on their level of physical development and the functional state achieved in the process of physical education.

The obtained results indicate a high degree of statistical probability of health-training classes of the third experimental subgroup. It should be noted that according to the experimental data and the questionnaire, the representatives of this subgroup significantly improved the performance of the cardiovascular, respiratory systems and musculoskeletal system. In particular, the girls' blood pressure was normalized from $116 / 66$ to $114 / 78 \mathrm{~mm} \mathrm{Hg}$; heart rate decreased from 87.6 to 82.3 beats $/ \mathrm{min}$. and body weight from 59,9 to $57,3 \mathrm{~kg}$; static balancing indicators improved from $17,3 \mathrm{~s}$ to $24,5 \mathrm{~s}$. and vital capacity of the lungs from 2263,5 to $2574,1 \mathrm{ml}$. The boys' blood pressure improved from $113 / 65$ to $118 / 74 \mathrm{~mm} \mathrm{Hg}$; heart rate from 86,3 to 80,7 beats/min; static balancing from $22,1 \mathrm{~s}$ to $27,2 \mathrm{~s}$; vital capacity of the lungs from 3267,8 to 3976,4 $\mathrm{ml}$; body weight from 67,8 to $70,1 \mathrm{~kg}$. Students improved their well-being, increased oxygen-regenerative processes in the body, normalized the activity of the gastrointestinal tract and excretory organs, and improved coordination between muscle activity and autonomic-trophic functions, and so on.

\section{Discussion}

Modern approaches in higher education for the conservation and promotion of health student youth are not sufficiently reflected in the educational process $[12,20,27,32]$. This is largely due to the fragmented understanding of the problem's teachers save student health [50-53].

The results of the conducted research acknowledge the data of other scientists in Ukraine and foreign countries on the positive impact of exercise on the physical condition of man $[9,11,13,39]$. At the same time, they complement these results by clarifying the sequence of health and training sessions; specify their content and algorithm in sections on individual sports [27, 53-55].

As a result of the pedagogical experiment, it has been found that a positive result of physical exercises is detected only starting with additional or specially organized [health and training classes in sports sections] four hours of independent classes per week. It has been 
proved that the greatest effect occurs with six or more independent hours of exercise per week, which together with two hours of compulsory physical education is eight hours per week. This is the minimum that students must follow to maintain good physical condition and health.

Our data partially agree with the findings of Dao Chanh Thuc [12], who examined the motor activity influence on BA of Vietnamese female students aged 17-18. It was found that one physical education class and six or more independent classes per week (equivalent to 17-20 hours of training) contributed to a significant BA decrease at the end of the experiment. In our studies, a decrease in the biological age of boys and girls was observed after four and six and more hours of regular additional exercises, respectively. The most pronounced changes in physical state indices, which determined biological age decrease during the academic year were noted in students, whose weekly motor regime exceeded 6 hours.

Our current and earlier researches provide several reasons to explain these results. The first and main reason is the insufficient number of hours of exercise for girls. Due to the fact that at secondary schools girls receive from 10 to $20 \%$ of the required motor activity $[1,50,51]$, in higher education institutions, research and teaching staff begin to work with physically unprepared girls.

Therefore, the number of hours for recovery, development and improvement of physical condition, motivation for self-improvement, providing them with the basics of physical education, requires much more than provided by the educational unit of the university.
The second reason is the low efficiency of health and training classes in physical education [32, 54-56].

The third reason is the non-observance of methodical recommendations by the scientific-methodical worker concerning the organization and system of conducting independent classes taking into account the chronotype of the personality.

The fourth reason is the lack of strict adherence to the daily routine (sleeping time no later than 22:00, rise at 7:00), diet, control of their emotional state, and so on.

The fifth reason is low methodological literacy in the matters related to the system of independent healthtraining classes.

The sixth reason is non-compliance with the schedule of independent health-training classes.

Perhaps there are other reasons [11, 16, 55-57]. But one way or another, they do not contribute to the desired effect of conducting classes on this system.

\section{Conclusions}

The author's system of health related and training classes in physical education can be considered a standard in determining the weekly motor regime of higher education institution students.

Elaborated mathematical models are recommended to be applied for estimating, modeling, and predicting the biological age of students according to informative indices of physical state.

\section{Conflict of interests}

The authors declare that there is no conflict of interests.

\section{References}

1. Apanasenko GL, Havruliuk V. Biological degradation of HOMO SAPIENS: ways of counteraction. Basics. Concepts. Methods. Palmarium Academic Publishing; 2014. (In Russian).

2. Prysiazhniuk SI, Oleniev DH, Parchevskyi YuM. Healthimproving physical culture of students of higher educational establishments of IT technologies: Kyiv: NULES of Ukraine; 2016. (In Ukrainian).

3. Aceijas C, Waldhausl S, Lambert N, Cassar S, Bello-Corassa $\mathrm{R}$. Determinants of health-related lifestyles among university students. Perspectives in PublicHealth. 2017;137(4):227-236. https://doi.org/10.1177/1757913916666875

4. Assaf I, Brieteh F, Tfaily M, El-Baida M, Kadry S, Balusamy B. Students university healthy lifestyle practice: quantitative analysis. Health Information Science and Systems. 2019;7. https://doi.org/10.1007/s13755-019-0068-2

5. Prysiazhniuk S, Tolubko V, Oleniev D, Parczevskyy Y, Prontenko K, Griban G, et al. The influence of physical activities on biological age parameters of the first-year female students from the special medical department. Journal of Physical Education and Sport, 2018; 18 (2): 561-64. https://doi.org/10.7752/jpes.2018.02081

6. Ferreira MJ, Pereira CS, Moreira F, Durao N. Digital transformation at high education: are professors of the south European and south American countries prepared for that? In: Chova LG, Martinez AL, Torres IC, editors. 13th International Technology, Education and Development
Conference. INTED Proceedings. 2019. P. 3610-3620. https://doi.org/10.21125/inted.2019.0929

7. Mammad M. Terms of post-secondary education management. In: Ibrahimov M, Aleksic A, Dukic D, editors. Economic and Social Development. International Scientific Conference on Economic and Social Development. 2019. P. 1031-1036.

8. Khalfieva AR, Yusupov MG. Study of students' cognitive states self-regulation during lessons. Journal of Human Sport and Exercise. 2020;15: 898-906. https://doi.org/10.14198/jhse.2020.15.Proc3.41

9. Griban G, Yahupov V, Svystun V, Dovgan N, Yeromenko E, Udych Z, et al. Dynamics of the Students' Physical Fitness While Studying at Higher Educational Institutions. International Journal of Applied Exercise Physiology. 2020; 9(9):147-156.

10.Guthold R, Stevens GA, Riley LM, Bull FC. Global trends in insufficient physical activity among adolescents: a pooled analysis of 298 populationbased surveys with 1.6 million participants. Lancet Child \& Adolescent Health. 2020; 4(1):23-35. https://doi.org/10.1016/s2352-4642(19)30323-2

11. ThomasAM,BeaudryKM,GammageKL,KlentrouP,JosseAR. Physical Activity, Sport Participation, and Perceived Barriers to Engagement in First-Year Canadian University Students. Journal of Physical Activity \& Health. 2019;16(6):437-446. https://doi.org/10.1123/jpah.2018-0198

12.Dao Chanh Thuc The influence of physical activities on 
biological age parameters of females from 17 to 18 years old. Journal of Sports Medicine and Therapy. 2018; 3: 075:079. https://doi.org/10.29328/journal.jsmt.1001030

13.Szwarc H. Influence of exercise and physical recreation on human somatic and mental health. In: Dąbrowski (ed). Zdrowie Psychiczne. Warsaw: PWN; 1985. P.231-243. (In Polish).

14.Cumming SP, Standage M, Gillison FB, Dompier TP, Malina RM. Biological maturity status, body size, and exercise behavior in British youth: a pilot study. J Sports Sci. 2009; 27: 677-86. https://doi.org/10.1080/02640410902725590

15.Muravov I.V. The capabilities of the human body. Moscow: Knowledge; 1988. (In Russian).

16. Verbin N, Shemchuk V, Oleniev D. The methodology of diagnostic of the future professional' level of physical preparation. Viiskova Osvita, 2020; 1 (41): 61-68. (In Ukrainian).

17.Prysiazhniuk SI, Krasnov VP. Experimental study of the dynamics of biological age of 1st year students of the National Agrarian University. Physical Education at School, 2004; 1: 50-53. (In Ukrainian).

18.Amosov NM. Amosov's Encyclopedia. Health algorithm. Moscow: AST Publishing House; Donetsk: Stalker; 2002. (In Russian).

19.Bulich EG. Medical substantiation of active rest in labor and educational activity. [dissertation]. Kyiv; 1994. (In Russian).

20.Prysiazhniuk SI. The use of health-saving technologies in the physical education of students of the special medical department. Theory and practice. Kyiv: COMPRINT; 2012. (In Ukrainian).

21.Dubinin NP. Social and biological in human development. In: The relationship between biological and social: Interuniversity collection of scientific papers. Perm: Perm University; 1981: P. 3-13. (In Russian).

22. Ananiev VA, Davydenko DN, Petlenko VP, Khomutov GA. Etudes of valeology. St. Petersburg.: St. STU; 2001. (In Russian).

23.Huckins JF, daSilva AW, Wang W, Hedlund E, Rogers C, Nepal SK, et al. Mental Health and Behavior of College Students During the Early Phases of the COVID-19 Pandemic: Longitudinal Smartphone and Ecological Momentary Assessment Study. J Med Internet Res, 2020;22:e20185. https://doi.org/10.2196/20185

24.Zhang Y, Zhang HY, Ma XD, Di Q. Mental Health Problems during the COVID-19 Pandemics and the Mitigation Effects of Exercise: A Longitudinal Study of College Students in China. International Journal of Environmental Research and Public Health. 2020;17(10):3722. https://doi.org/10.3390/ijerph17103722

25.Gallo LA, Gallo TF, Young SL, Moritz KM, Akison LK. The Impact of Isolation Measures Due to COVID-19 on Energy Intake and Physical Activity Levels in Australian University Students. Nutrients. 2020;12(6):1865. https://doi.org/10.3390/nu12061865

26.Romero-Blanco C, Rodriguez-Almagro J, Onieva-Zafra MD, Parra-Fernandez ML, Prado-Laguna MD, HernandezMartinez A. Physical Activity and Sedentary Lifestyle in University Students: Changes during Confinement Due to the COVID-19Pandemic. International Journal of Environmental Research and Public Health. 2020;17(18):6567. https://doi.org/10.3390/ijerph17186567

27.Prysiazhniuk SI, Oleniev DH, Krasnov VP. Physical education of students as a component of vocational education: Text edition. Kyiv: NULES of Ukraine; 2018. (In
Ukrainian)

28.Osipenko EV. Self-Assessment of Physical Health by Students of Francisk Skorina Gomel State University. Tomsk State University Journal. 2019;439:173-177. https://doi.org/10.17223/15617793/439/24

29.Hossain S, Anjum A, Hasan MT, Uddin ME, Hossain MS, Sikder MT. Self-perception of physical health conditions and its association with depression and anxiety among Bangladeshi university students. Journal of Affective Disorders. 2020; 263:282-288. https://doi.org/10.1016/j.jad.2019.11.153

30.Pavlovskyi OM. Human biological age. Moscow: Moscow University Publishing House; 1987. (In Russian).

31.Voitenko VP. Determination of biological age as a problem of theoretical and practical medicine. Modern Problems of Gerontology and Geriatrics, 1988; 2: 2-30. (In Russian).

32.Prysiazhniuk SI. Biological age and health of student youth: Monography. Kyiv: Center for Educational Literature; 2010. (In Ukrainian).

33.Jinho Yoo, Yangseok Kim, Eo Rin Cho, Sun Ha Jee. Biological age as a useful index to predict 17-year survival and mortality in Koreans. BMC Geriatrics. 2017; 17: 7. https://doi.org/10.1186/s12877-016-0407-y

34.Kang YG, Suh E, Lee JW, Kim DW, Cho KH, Bae CY Biological age as a health index for mortality and major age-related disease incidence in Koreans: National Health Insurance Service - Health screening 11-year followup study. Clin Interv Aging. 2018. Mar 20; 13: 429-436. https://doi.org/10.2147/CIA.S157014

35.Zhong $\mathrm{X}, \mathrm{Lu} \mathrm{Y}$, Gao Q, Nyunt MSZ, Fulop T, Monterola CP, et al. Estimating Biological Age in the Singapore Longitudinal Aging Study. The Journals of Gerontology: Series A, 2020;75:1913-20. https://doi.org/10.1093/gerona/glz146

36.VerschoorCP,BelskyDW,MaJ, CohenAA, GriffithLE, RainaP. Comparing Biological Age Estimates Using Domain-Specific Measures From the Canadian Longitudinal Study on Aging. The Journals of Gerontology: Series A, 2021;76:187-94. https://doi.org/10.1093/gerona/glaa151

37.Belsky DW, Caspi A, Houts R, Cohen HJ, Corcoran DL, Danese A, et al. Quantification of biological aging in young adults. Proc Natl Acad Sci USA, 2015;112:E4104-10. https://doi.org/10.1073/pnas.1506264112

38.Jee H, Jeon BH, Kim YH, Kim H-K, Choe J, Park J, et al. Development and Application of Biological Age Prediction Models with Physical Fitness and Physiological Components in Korean Adults. Gerontology, 2012;58:344-53. https://doi.org/10.1159/000335738

39.Bacil EDA, Mazzardo Júnior O, Rech CR, Legnani RF dos S, Campos W de. Physical activity and biological maturation: a systematic review. Revista Paulista de Pediatria, 2015;33:114-21. (In Portuguese). https://doi.org/10.1016/j.rpped.2014.11.003

40.Simm A, Nass N, Bartling B, Hofmann B, Silber R-E, Navarrete Santos A. Potential biomarkers of ageing. Biological Chemistry, 2008;389:257-65. https://doi.org/10.1515/BC.2008.034

41.Pavanello, Campisi, Tona, Lin, Iliceto. Exploring Epigenetic Age in Response to Intensive Relaxing Training: A Pilot Study to Slow Down Biological Age. International Journal of Environmental Research and Public Health, 2019;16:3074. https://doi.org/10.3390/ijerph16173074

42.Rahman SA, Adjeroh DA. Estimating Biological Age from Physical Activity using Deep Learning with 3D CNN. In: Yoo IH, Bi JB, Hu X, editors. Ieee International Conference 
on Bioinformatics and Biomedicine. IEEE International Conference on Bioinformatics and Biomedicine-BIBM. 2019. P. 1100-1103.

43.Ajman $\mathrm{H}$, Tomac $\mathrm{Z}$. Differences in biological age of the best U11 and U13 teams in Croatia. Journal of Human Sport and Exercise. 2019;14: 2375-2379. https://doi.org/10.14198/jhse.2019.14.Proc5.52

44.Goto H, Morris JG, Nevill ME. Influence of biological maturity on the match performance of 8-to 16-year-old, elite, male, youth soccer players. Journal of Strength and Conditioning Research. 2019;33(11):3078-3084. https://doi.org/10.1519/jsc.0000000000002510

45.Lesinski M, Schmelcher A, Herz M, Puta C, Gabriel $\mathrm{H}$, Arampatzis A, et al. Maturation-, age-, and sexspecific anthropometric and physical fitness percentiles of German elite young athletes. Plos One. 2020;15(8). https://doi.org/10.1371/journal.pone.0237423

46. World Medical Association Declaration of Helsinki: Ethical Principles for Medical Research Involving Human Subjects. JAMA, 2013;310:2191. https://doi.org/10.1001/jama.2013.281053

47.Koryahin V, Turchyn Y, Blavt O, Dolnikova L. Information Systems of Support of Pedagogical Control in the Physical Education of Students. Teoriâ Ta Metodika Fìičnogo Vihovannâ, 20(4), 205-211. https://doi.org/10.17309/tmfv.2020.4.02

48. Voitenko VP. Health of the healthy. Introduction to Sanology. Kyiv: Health; 1991. (In Russian).

49.Borovikov VP, Ivchenko GI. Prognostication in the system of Statistica in the environment of Windows. Moscow: Finances and statistics; 2006. (In Russian).

50.Amosov NM, Muravov IV. Heart and physical exercises. Kiev: Health; 1985. (In Russian).

51.Bulich EG, Muravov IV. Human health: The biological basis of life and physical activity in its stimulation. Kyiv: Olympic literature; 2003. (In Russian).

52.Shafranovkyi AK. Biological age and health of the population. Healthcare. International magazine, 1985; 28(1): 55-66. (In Russian).

53. Chebotariov DF, Yaroshchenko YuT. Premature (accelerated) aging: causes, diagnosis, prevention and treatment. Medical Universe, 2001; 1(1): 28-38. (In Russian).

54.Prysiazhnyuk S, Pryimakov O, Oleniev D, Ejder E, Popov $\mathrm{M}$, Kolenkov O. Research health-keeping technologies in the system of physical education of students from special medical groups. Journal of Physical Education and Sport, 2019; 19 (3): 1663-1669.

55.Prysiazhniuk S, Oleniev D, Tiazhyna A, Popov M, Semerun V, Parczevskyy Y, et al. Methods of Development of Physical Qualities of Schoolchildren of the Sixth Grade Depending on the Volume of the Physical Activity. International Journal of Applied Exercise Physiology, 2019; 8 (3.1): 87-94.

56.Pryimakov AA, Dotsenko EN. Problems of university physical education as a factor in strengthening health and improving motor capacities of students. Pedagogics, Psychology, Medical-Biological Problems of Physical Training and Sports. 2006; 5: 83-88. (In Russian).

57.Prysiazhniuk SI. Relationship between biological age and state of physical fitness of NAU students. Theory and Practice of Physical Education, 2004; 1: 21-25. (In Ukrainian).

\section{Information about the authors:}

Stanislav Prysiazhniuk; (Corresponding author); Doctor of Pedagogical Sciences, Professor; http://orcid.org/0000-0002-30170268; stas046@ukr.net; Department of Life Safety and Physical Education, University of Telecommunications; Kiev, Ukraine.

Oleksandr Pryimakov; Doctor of Biological Sciences, Professor; http://orcid.org/0000-0003-0351-486X; sanaol7.alex@gmail. com; Institute of Physical Culture Sciences, Szczecin University; Szczecin, Poland.

Sergii lermakov; Doctor of Pedagogical Sciences, Professor; http://orcid.org/0000-0002-5039-4517; sportart@gmail.com; Department of Sport, Gdansk University of Physical Education and Sport; Gdansk, Poland.

Dmytro Oleniev; Doctor of Pedagogical Sciences, Assistant Professor; http://orcid.org/0000-0001-9685-725X; kaf.fv.dut@ gmail.com; The Chair of Theory, Methodology and Organization of Physical Training and Sports, Educational and Scientific Institute of Physical Culture and Sports and Health Technologies, The National Defence University of Ukraine named after Ivan Cherniakhovskyi; Kiev, Ukraine.

Jerzy Eider; Doctor of Pedagogical Sciences, Professor, http://orcid.org/0000-0002-8401-6442; erzy.eider@usz.edu.pl; Institute of Physical Culture Sciences, Szczecin University; Szczecin, Poland.

Natalija Mazurok; Master Degree “Physical Education and Sport”, https://orcid.org/0000-0001-7346-1156; natprim75@gmail. com; National Pedagogical Dragomanov University;Kyiv, Ukraine.

Cite this article as:

Prysiazhniuk S, Pryimakov O, lermakov S, Oleniev D, Eider J, Mazurok N. Influence of weekly physical exercises on indicators of biological age of student's youth. Physical Education of Students, 2021;25(1):58-66. https://doi.org/10.15561/20755279.2021.0108

This is an Open Access article distributed under the terms of the Creative Commons Attribution License, which permits unrestricted use, distribution, and reproduction in any medium, provided the original work is properly cited http://creativecommons.org/licenses/by/4.0/deed.en

Received: 03.01.2021

Accepted: 22.02.2001; Published: 26.02.2021 